\title{
UMA CONCEPÇÃo DE CIDADANIA (PLANETÁRIA) PARA A FORMAÇÃO CIDADÃ
}

\author{
Jaciara de SÁ Carvalho \\ Universidade Estácio de Sá (UNESA), Rio de Janeiro, Brasil
}

\begin{abstract}
ResUmo: Este trabalho apresenta uma compreensão de cidadania fundamentada em estudo da obra de Paulo Freire (1979, 2001, 2009b) devido às suas contribuições para a formação cidadã. Argumenta-se que a cidadania pode ser compreendida como condição permanentemente conquistada por meio do desenvolvimento da consciência crítica. A investigação partiu de uma análise de conteúdo, considerando subsídios metodológicos de Bardin (1988). Mas, sobretudo, está baseada no conceito de "conscientização"em Freire (1979), cujo processo poderia promover a participação ativa de sujeitos na construção de outras realidades, em acordo com visões contemporâneas que associam cidadania à participação ativa em todo o planeta. Ao final, uma cidadania de caráter planetário é identificada como adequada às discussões e práticas de educação cidadã.

Palavras-Chave: Paulo Freire. Cidadania planetária. Educação. Conscientização.
\end{abstract}

\section{INTRODUÇÃO'}

Cidadania é uma palavra que remete à defesa de direitos e exercício de deveres. Sob uma abordagem sociológica, uma definição de cidadania pode ser a de status dentro de uma comunidade nacional ou política. Esse conceito, também segundo Giddens e Sutton (2016), divide-se em diferentes tipos, cada um criado a partir do anterior: cidadania civil, política social, ambiental/ ecológica (nos últimos anos). Em paralelo, discussões sobre cidadania global, 
ou planetária (em uma vertente emancipatória), vêm contestando definições circunscritas à ideia de Estado-nação, como será tratado adiante.

$O$ termo cidadania fez surgir diversas teorias a seu respeito na última década do século XX. Entre as razões para que esse conceito tenha ganhado mais visibilidade no período, Cortina (2009) destaca a necessidade das sociedades pós-industriais de gerarem um tipo de identidade entre seus membros, nas quais se reconheçam e que crie um sentimento de pertencimento a elas. A preocupação estaria na falta de interesse pelos desafios que se apresentam a todos e, sem essa adesão, seria impossível responder conjuntamente a eles. Haveria uma apatia cada vez maior quanto às questões coletivas, prevalecendo a busca pela satisfação de desejos pessoais, com pouco afeto pela comunidade da qual participam e nenhuma disposição para sacrificar-se por ela.

A participação ativa, efetiva e democrática seria fundamental para a construção de sociedades mais justas e inclusivas (GIL-JAURENA et al., 2011). Mas isso implica que os sujeitos não se restrinjam apenas às suas aspirações individuais e ao voto como forma de participação (LLORENTE CORTÉS, 2006), assumindo também para si a responsabilidade por projetos coletivos.

Não são poucas as teorias sobre cidadania, em sua maioria, produzidas fora da área da Educação. Nesta, há diversos trabalhos a respeito da "formação para cidadania", um dos objetivos da educação nacional (BRASIL, 1996) sob aspectos e expressões distintos, como "educação para a democracia" (PARO, 2000), "escola cidadã" (GADOTTI, 2010) e "educação democrática" (BIESTA, 2013). Neste artigo, entretanto, nos restringimos a comunicar - ainda que sob estudos introdutórios - uma concepção inicial de cidadania que parte de um autor referência na área; no caso, Paulo Freire (1921-1997), reconhecendo-se suas contribuições para uma educação cidadã. ${ }^{2}$

Considerando aspectos metodológicos de Bardin (1988), este trabalho partiu de uma análise de passagens nas quais o termo "cidadania" aparece em algumas publicações de Freire (1979, 2001, 2009b), buscandose, entretanto, considerar o pensamento do autor também desenvolvido em outras obras (1995, 1996, 2009a). Mas, sobretudo, a ideia de cidadania desenvolvida neste trabalho considera o conceito de "conscientização" (FREIRE, 1979) e o diálogo com outros autores (LOZANO, 1996; SANTOS, 2002; GADOTTI, 2008; MORIN, 2010) acerca de uma cidadania de caráter planetário.

\section{Cidadania, a partir de Paulo Freire}

Ao pé da letra, encontramos em Freire (2001, p. 25) a expressão "cidadania" como "condição de cidadão, quer dizer, com o uso dos direitos e o 
direito de ter deveres de cidadão". Quer dizer, usufruindo tudo aquilo a que teria direito, encontrando-se em situação de servir-se do que seria seu por direito.

Entretanto, a leitura de conjunto de parte de sua obra sugere que cidadania não seria uma qualidade a priori, como uma condição que é própria do sujeito em sociedades democráticas. Para além do pé da letra, entende-se que cidadania seria uma condição a ser conquistada por aqueles que não a usufruem ou o fazem em parte. Também por quem deseja criar e/ou modificar novos direitos e deveres de acordo com valores que possam tornar melhores as condições da existência humana. Cidadania seria um estado constante de "posse da realidade" (FREIRE, 1979, p. 16) e, para isso, implicaria ao sujeito desenvolver criticidade na sua relação com o mundo e os outros.

Encontramos em Freire passagens que confirmariam a ideia de cidadania como uma condição que não é pronta, que precisa ser construída pelos sujeitos em comunhão com os demais. Para isso, uma educação (libertadora) pode ser grande aliada. "Está aqui uma das questões centrais da educação popular - a da linguagem como caminho de invenção da cidadania" (2009b, p. 41, grifo nosso). A educação que contribui para inventar a cidadania é "problematizadora" (1979, p. 42), fundada na criatividade, na ação-reflexão sobre a realidade.

Assistimos a uma sessão de um "Círculo de Cultura" em que militantes armados se alfabetizavam, aprendiam a ler palavras fazendo a releitura do mundo. $\mathrm{O}$ aprendizado da escrita e da leitura da palavra, que faziam na compreensão do discurso, emergia ou fazia parte de um processo maior e mais significativo - o da assunção de sua cidadania, o da tomada da história em suas mãos. É isso que sempre defendi, é por isso que sempre me bati por uma alfabetização que, conhecendo a natureza social da aquisição da linguagem, jamais a dicotomize do processo político da luta pela cidadania (FREIRE, 2009b, p. 199).

A "luta pela cidadania", como destacada no trecho citado, implicaria, necessariamente, consciência sobre a natureza política de intervenção no mundo. A clareza da não neutralidade nos escritos de Freire sobre educação, grosso modo, diz respeito a reconhecer que as ações humanas estão sempre "a favor de alguém [algo] e contra alguém [algo]" (2001, p. 22). Esta é a tônica, também, na obra Política e educação, na qual Freire tem um capítulo sob o título "Alfabetização como elemento de formação de cidadania" (2001, p. 13). Nele, ao final, resume que "ler e escrever não são suficientes para perfilar a plenitude da cidadania". Essa formação depende do compromisso do educador com a politicidade do ato de educar, depende que a formação seja "como um ato político, jamais como um que fazer neutro" (2001, p. 30). 
Segundo Herbert (2010, p. 67), "a educação com vistas à cidadania é o objetivo de Freire desde o começo de sua atuação como educador".

Apesar de não recorrer com frequência ao emprego da palavra "cidadania" em seus escritos, nosso estudo tornou possível sua associação com o que poderia ser chamado de categorias freirianas, como "ser mais" (FREIRE, 2001, p. 45). Cidadania poderia ser relacionada à luta permanente dos sujeitos para conquistar uma condição digna para si e os demais. Até porque faria parte da natureza humana a busca constante em "ser mais", como sentido de sua existência. É recorrente na teoria freiriana o uso dessa expressão, como vocação ontológica para a humanização. Por ser vocação, não é inata ou determinada pelas estruturas, mas algo que se constitui na história como possibilidade. Zitkoski (2010) explica o sentido antropológico de "ser mais" em Freire:

É a própria natureza humana em seu modo de existir na história - por implicar um constante autofazer-se no mundo humano - que, no entender de Freire (1995; 1997), o habilita a definir a vocação ontológica do ser humano como a luta pela humanização. Ante as realidades históricas de desumanização de milhões de pessoas no mundo todo (que constitui a própria negação dessa vocação ontológica), a luta por humanização funda-se antropologicamente e eticamente no processo de construção desse ser inconcluso, que busca recuperar sua humanidade e/ou superar o atual estágio de afirmação de seu ser mais. Esse é o sentido antropológico que devemos conferir à existência humana (ZITKOSKI, 2010, p. 370, grifo do autor).

Essa busca ou afirmação do "ser mais" poderia ser relacionada à cidadania - nos termos aqui discutidos - na medida em que ambas se configuram como luta por condições que permitam aos sujeitos (individual e coletivamente) usufruírem de meios promotores dessa vocação. $O$ acesso à saúde, à justiça e à educação - de caráter emancipatório -, por exemplo, contribuiria com a construção de níveis mais elevados de humanização.

Nesse sentido, mais do que um status atribuído pela visão sociológica, cidadania pode ser compreendida como um estado a ser conquistado pelos sujeitos, coletivamente, principalmente em países com sérias desigualdades econômicas e sociais como o Brasil, com serviços públicos precários e pouca efetivação de direitos historicamente definidos (ainda que sob um modelo de sociedade liberal).

Entretanto, a reinvindicação de direitos e a participação ativa contra as muitas formas de opressão exigem criticidade por parte dos sujeitos. "A luta pela cidadania", como Freire (2009b, p. 199) assinalou, demanda - segundo os estudos realizados - permanente esforço de "conscientização" pelos sujeitos em sua relação com o mundo e com os outros. Neste trabalho, o conceito 
(ou categoria) de "conscientização" em Freire (1979) foi identificado como fundamental para uma compreensão de cidadania que pudesse subsidiar discussões sobre educação cidadã.

\subsection{CONSCIENTIZAÇÃO: COMPROMISSO HISTÓRICO COM A TRANSFORMAÇÃO DA REALIDADE}

Ninguém luta contra as forças que não compreende, cuja importância não mede, cujas formas e contornos não discerne [...] É preciso, portanto, fazer desta conscientização o primeiro objetivo de toda educação: antes de tudo provocar uma atitude crítica, de reflexão, que comprometa a ação (FREIRE, 1979, p. 22, grifo nosso).

Conscientização é um conceito estruturante na obra freiriana e pode ser entendido como um processo permanente de reflexão crítica acompanhada de ação transformadora, por meio da relação consciênciamundo, e que pressupõe a utopia.

Freire não foi o inventor dessa expressão, mas, por conta do conteúdo político-pedagógico que a ela conferiu, e que correu o mundo, muitos a ele atribuem a autoria. Em conversa com Carlos Alberto Torres (1998), Freire sintetiza o que seria a "conscientização":

A expressão francesa prise de conscience, tomar consciência de, é um modo normal de ser um ser humano. Conscientização é algo que está para além da prise de conscience. É algo que começa com a capacidade de conseguir, de ter a prise de conscience. Algo que implica analisar. É uma forma de ver o mundo rigorosamente ou quase rigorosamente. É uma forma de ver como a sociedade funciona. É o modo de compreender melhor o problema dos interesses, a questão do poder. Como obter poder, o que significa não ter poder. Finalmente, implica uma leitura mais profunda da realidade (e) o senso comum estando para além do senso comum (FREIRE apud TORRES, 1998 , p. 58, grifos do autor).

Segundo Freire $(1979,1996)$, ao aproximar-se pela primeira vez de um objeto/ mundo, impulsionado pela curiosidade que é própria do humano, o sujeito toma consciência dele. É uma tomada de consciência superficial que, por ser provocada por uma "curiosidade ingênua", resulta em um saber comum ou "saber de experiência feito" $(1996$, p. 18) - expressões recorrentes em sua obra. $O$ processo de conscientização seria justamente $o$ aprofundamento da criticidade do sujeito em sua relação com esse mesmo objeto/mundo, em ação dialética entre a consciência do sujeito e aquilo que vem sendo estudado e transformado, transformando-o ao mesmo tempo. É 
para esclarecer dimensões obscuras da realidade que o homem assumiria o desafio de tomar essa relação como objeto de sua reflexão.

O processo de conscientização implica a superação da "curiosidade ingênua" pela "crítica", também chamada por Freire (1996, p. 9) de "curiosidade epistemológica". A "crítica", nesse caso, é uma qualidade atribuída ao substantivo "curiosidade", motor do processo de conhecimento, próprio da experiência vital, que se aperfeiçoa na existência do mundo e vai sendo histórica e socialmente construída e reconstruída. Não há uma ruptura entre a curiosidade ingênua e a crítica, nem uma passagem automática, mas uma superação. A diferença estaria na rigorosidade metódica durante o estudo do objeto, do qual se toma distância para dele se aproximar e "falar prudentemente" (FREIRE, 2001, p. 55).

Como o conceito de conscientização atenderia a uma concepção de cidadania?

Entende-se que a efetivação de direitos e de melhores condições para que todos possam "ser mais" depende, em grande medida, do desenvolvimento da criticidade pelos próprios sujeitos que, na acepção freiriana, não se faz separada da participação ativa para a transformação da realidade opressora.

Como escrito no início deste artigo, a participação ativa seria uma das principais expressões de cidadania. No entanto, não se trata aqui nem de qualquer concepção de cidadania nem de participação; não basta participar ativamente para contribuir com a transformação comprometida com a humanização. Trata-se de uma participação ativa crítica, aquela não fundamentada nem no espontaneísmo nem no "ativismo", que Freire (2009a, p. 59) considerava como um agir sem reflexão, aproximando-o do sectarismo, "que tem uma matriz preponderantemente emocional e acrítica". Mas na busca incessante por compreender relações de poder, engajada em uma leitura aprofundada da realidade para intervir.

A expressão participação ativa tratada aqui poderia ser substituída pela palavra "engajamento", utilizada por Freire em uma conferência no México em 19713, ao explicar que"não há conscientização sem compromisso histórico":

[conscientização] É inserção crítica na história.

[...] Descobrir-se oprimido só começa a ser processo de libertação quando esse descobrir-se oprimido se transforma em compromisso histórico que significa engajamento. Engajamento [...] é exatamente a inserção crítica na história para criá-la, para fazê-la. Portanto, se apesar da percepção de que é oprimido, o homem não se compromete, daí em diante, em um processo 
de transformação da realidade concreta opressora, não há compromisso histórico neste homem e, por essa razão, não está conscientizado (FREIRE apud TORRES, 2014, p. 76, grifo nosso).

Em continuação a esse trecho, Freire destaca que seria idealismo (filosófico) o sujeito acreditar ser livre apenas após reconhecer-se como oprimido, uma vez que as estruturas opressoras continuariam existindo e, logo, não haveria libertação de fato.

Não se desconsidera que o contexto no qual Freire apresentou essas reflexões era anterior a processos de redemocratização na América Latina nem que a exploração de trabalhadores rurais o tenha inspirado em escritos sobre "conscientização", como o de 1971. Mas entende-se que alguns conceitos como este continuam atuais, pois a forma como foram desenvolvidos ainda contribuem para subsidiar discussões e construir práticas para enfrentar desafios atuais. Além do mais, as formas de opressão podem mudar, mas não deixaram de existir. Se é que um dia deixarão.

A esse respeito, ressalte-se que conceber cidadania como condição conquistada pelo processo permanente de conscientização, que implica engajamento/participação ativa, exige uma "postura utópica diante do mundo". Utopia como "dialetização nos atos de denunciar [a estrutura desumanizante] e anunciar [a estrutura humanizadora]" (FREIRE apudTORRES, 2014, p. 76).

Ressalte-se, ainda, que o processo de conscientização nunca se esgota. Ao esclarecer uma relação, esta logo se apresenta como nova realidade, que precisa ser novamente objeto de criticidade para que o sujeito não caia na armadilha ingênua e reacionária de acreditar que não há nada mais para ser revelado, ainda mais considerando que o objeto cognoscível, assim como o sujeito, está em constante movimento. Por isso, "a conscientização é [..] um teste de realidade", que, quanto mais desvelada, "mais se penetra em sua essência fenomênica" e, por isso, não se faz "fora da práxis" (FREIRE, 1979, p. 15), da prática cidadã, da participação ativa crítica e utópica.

\section{Cidadania e planetaridade}

A compreensão de cidadania aqui tratada integraria uma das visões contemporâneas que associa cidadania à participação ativa em todo o planeta, enfatizando a responsabilidade compartilhada. Embora as obras de Freire fossem marcadas pelo contexto de ditaduras militares, tanto no Brasil como em outros países, e alguns de seus livros nos remetessem à defesa da cidadania junto ao Estado-nação, a totalidade de sua produção sugere que 
democracia e cidadania, como valores, condições e práticas, não se restringem a cada país, individualmente.

Freire se dizia um cidadão do mundo (1995), a partir do Nordeste brasileiro, e sua perspectiva "cidadã" abarca a humanidade e a nossa morada comum - tanto que suas obras ressoam em práticas no mundo todo, não apenas no Ocidente.

Antes de tornar-me um cidadão do mundo, fui e sou um cidadão do Recife, a que cheguei a partir de meu quintal, no bairro de Casa Amarela. Quanto mais enraizado na minha localidade, tanto mais possibilidades tenho de me espraiar, me mundializar. Ninguém se torna local a partir do universal. O caminho existencial é inverso. Eu não sou antes brasileiro para depois ser recifense. Sou primeiro recifense, pernambucano, nordestino. Depois, brasileiro, latino-americano, gente do mundo (FREIRE, 1995, p. 25).

Historicamente, a noção de cidadania tem sido limitada, ainda que conceitualmente, pelo Estado-nação, mesmo que uma visão de sociedade civil global se desenvolva desde o século XVIII (LOZANO, 1996). Essa ideia de cidadania restrita tem sido questionada principalmente a partir do avanço de inovações tecnológicas e do processo de globalização ${ }^{4}$ que tornou mais perceptível a relação entre as ações humanas; predominantemente, pela marca da destruição e da desigualdade. Constata-se que vivemos uma crise de paradigmas e de incertezas provocadas pelo modelo econômico neoliberal e pelo desenvolvimento de tecnologias digitais.

Segundo Cortina (2002, s.p), desde o último terço do século XX, "la racionalidad mesológica, la que entiende de medios más que de fines" ${ }^{\prime \prime}$, tem fincado suas bases em uma sociedade global, servindo-se do progresso técnico e do capitalismo financeiro. Pela primeira vez na história, acredita a autora, existem meios suficientes para realizar o sonho de uma cidadania cosmopolita ${ }^{5}$, mas também de arrasar o planeta e destruir grande parte da humanidade e países em fração de segundos.

Se, por um lado, o modelo de globalização capitalista, "globalista" (IANNI, 1996), aprofundou as diferenças entre os sujeitos/povos/nações e contribuiu para a perda de autonomia dos Estados, por outro, acabou por escancarar o óbvio, que as ações humanas estão conectadas mundialmente, para o fato de que os problemas (e as soluções) podem ser comuns porque o planeta também o é. "Por lo que hay que preguntarse ¿si los derechos ciudadanos se especifican y definen sólo respecto de la entidad política del estado-nación? [...] en el contexto contemporáneo, ya no es ello posible" ${ }^{\prime \prime}$, acredita Lozano (1996, s.p). No entanto, já advertia o autor na época, a"cidadania 
global", mais que uma realidade palpável, é um processo de construção e uma aspiração política por ter de confrontar, e negociar com, os poderes.

Exemplos dessa realidade de difícil concretização estão sendo presenciadas ou vividas neste início de século XXI. Nos Estados Unidos, o presidente Donald Trump foi eleito em 2017 com um discurso discriminatório, anti-imigração e de supremacia sobre as demais nações. A Agência da ONU para Refugiados (2016) registrou 65,3 milhões de pessoas deslocadas por conflitos e guerras durante o ano de 2015 e informa que "nos países industrializados, 3,2 milhões aguardavam no final de 2015 a resposta a suas solicitações de refúgio - o maior número já registrado pelo ACNUR".

São dados da realidade que tornariam urgente o aprofundamento de discussões e estratégias em favor de uma cidadania de caráter planetário. Gadotti (2008), Santos (2002) e Morin (2010) são alguns autores que relacionam as palavras "cidadania" e "planeta" empregando, algumas vezes, a expressão "cidadania planetária" em posição contrária à visão de mundo hegemônica neoliberal, à globalização competitiva, a valores contrários à ideia de que vivemos em uma morada comum.

A noção de cidadania planetária se sustenta em uma visão unificadora do planeta, na perspectiva de uma sociedade mundial. Ela tem raízes históricas em movimentos, fóruns e declarações em defesa do meio ambiente e de uma cultura de justiça e paz-"justipaz"; mas, principalmente, no desenvolvimento de uma cultura de sustentabilidade, que vem se beneficiando dessas ações e reflexões e se baseia em um "paradigma filosófico (Paulo Freire, Leonardo Boff, Sebastião Salgado, Boaventura de Souza Santos, Edgar Morin, Milton Santos) emergente na Educação que propõe um conjunto de saberes e valores interdependentes" (GADOTTI, 2008, p. 74, grifo nosso) para uma vida sustentável.

Ela [a noção de cidadania planetária] se manifesta em diferentes expressões: "nossa humanidade comum","unidade na diversidade","nosso futuro comum”, "nossa pátria comum". Cidadania planetária é uma expressão adotada para expressar um conjunto de princípios, valores, atitudes e comportamentos que demonstram uma nova percepção da Terra como uma única comunidade. Frequentemente associada ao "desenvolvimento sustentável", ela é muito mais ampla do que essa relação com a economia. Trata-se de um ponto de referência ético indissociável da civilização planetária e da ecologia (GADOTTI, 2008, p. 30, grifo nosso).

Esse paradigma ressalta a interdependência, a interconexão, o sentimento de somos"seres humanos y ciudadanos del planeta; ciudadanos del planeta Tierra que viven y comparten una comunidad de destino"s, como 
afirma Morin (2010, p. 437, grifo do autor). Segundo Lozano (1996, s.p), a "ecologia" tem contribuído com a ideia, nesse contexto, de cidadão global com raízes socioculturais vinculado a um lugar, "y con una solidaridad con la libertad y los derechos de todos los seres que habitan la tierra" ${ }^{\prime \prime}$. Embora mais associada às questões ambientais, Gadotti $(2008$, p. 32) ressalta que a cidadania planetária não pode ser apenas ambiental porque a fome, o analfabetismo, o preconceito, a discriminação, o tráfico, a corrupção "tiram a vida do planeta".

Neste projeto, entra ainda uma visão de Tecnologias de Informação e Comunicação (TICs) como direito humano, considerando que "os resultados tecnológicos são frutos de trabalho coletivo de milhões de homens de todas as classes sociais ou grupos de poder no decurso da história" (ALMEIDA, 2011, p. 11). A apropriação crítica das TICs cada vez mais se torna elemento-chave para a construção de sociedades sustentáveis em suas múltiplas dimensões.

Assim, o discurso dos direitos se soma com o das responsabilidades. A chave da noção de responsabilidade "no reside, por tanto, en las prédicas y las moralinas, sino en la existencia de vínculos entre los seres humanos o con la naturaleza, o en la capacidad de crearlos, pero sabiendo que es de ley cumplir los pactos"10 (CORTINA, 2002, s.p).

De fato, a cidadania planetária é uma utopia. "[...] mas todas as grandes ideias, antes de se realizarem, foram considerados utópicas", afirma Santos (2002). Para o autor, o conceito de sociedade civil nacional atende ao modelo liberal e, portanto, constitui um falso universalismo: nem todos têm direitos, muitos não são cidadãos, ficaram fora do contrato social e encontramse em estado natural. E pergunta-se (SANTOS, 2002): "por que vamos recorrer neste momento ao conceito de sociedade civil planetária para resolver o problema? Por que não somos capazes de pensar o novo senão a partir do velho, e de conceitos que estão à nossa disposição a serem retrabalhados."

Para Santos (2002), o embrião da sociedade civil planetária que se deseja construir é formado por uma parte da atual sociedade civil: os oprimidos, ou seja, os que não são considerados cidadãos (que lutam para adquirir cidadania e fazer parte do contrato social), além do Terceiro Setor (organizações solidárias, ONGs, movimentos sociais). A construção da sociedade planetária implica lutas que devem se articular em três escalas: local, nacional e global. A mobilização, interconectada, demanda a unidade na diversidade (FREIRE, 2009b; SANTOS, 2002).

Num primeiro momento a luta pela unidade na diversidade, que é obviamente uma luta política, implica a mobilização e a organização das forças culturais em que o corte de classe não pode ser desprezado, no sentido da 
ampliação e no do aprofundamento e superação da democracia puramente liberal. É preciso assumirmos a radicalidade democrática para a qual não basta reconhecer-se, alegremente, que nesta ou naquela sociedade, o homem e a mulher são de tal modo livres que têm o direito até de morrer de fome ou de não ter escola para seus filhos e filhas ou de não ter casa para morar. O direito, portanto, de morar na rua, o de não ter velhice amparada, o de simplesmente não ser (FREIRE, 2009b, p. 157, grifo nosso).

A sociedade civil planetária também poderia ser construída sob relações horizontais, sendo necessário buscar formas de organização plural e tolerante. Somente juntos podemos chegar à diversidade, avançar na criação de espaços transnacionais públicos "onde seja possível uma outra noção de direitos", que desmascarem as desigualdades (SANTOS, 2002).

A prática cidadã, quando realizada de forma coletiva, possui maior potencial de transformação. Afinal, em uma perspectiva histórica, "os movimentos sociais foram e continuam a ser as alavancas da mudança social" (CASTELLS, 2013, s.p). Rolnik (2013) observa que os movimentos estão se organizando de forma muito mais ampla "que a militância de partidos de esquerda e sindicatos, e não são estruturados pela lógica, métodos e práticas da política tradicional brasileira". Alguns sujeitos vêm utilizando instrumentos próprios para se auto-organizarem, como explica Castells (2013, s.p) em entrevista:

O que muda atualmente é que os cidadãos têm um instrumento próprio de informação, auto-organização e automobilização que não existia. Antes, se estavam descontentes, a única coisa que podiam fazer era ir diretamente para uma manifestação de massa organizada por partidos e sindicatos, que logo negociavam em nome das pessoas. Mas, agora, a capacidade de auto-organização é espontânea. Isso é novo e isso são as redes sociais. E o virtual sempre acaba no espaço público. Essa é a novidade. Sem depender das organizações, a sociedade tem a capacidade de se organizar, debater e intervir no espaço público (EQUIPE FRONTEIRAS, 2013).

É preciso ressaltar, entretanto, que a automobilização e a organização em redes sociais não têm, necessariamente, compromisso com valores compatíveis com a perspectiva planetária tratada, ainda que seja óbvio, mas alguns discursos utópicos acabam por desconsiderar essa questão. A participação em rede visando a transformações (quais? Em que direção?), ainda que comece localmente e depois passe para escala internacional, pode ser fruto de ativismo acrítico - como abordado anteriormente.

Relacionando esse tipo de mobilização e formação cidadã, Carvalho (2016, p. 1148) defende que a articulação de uma educação de caráter 
emancipatório com movimentos sociais em rede"pode ser uma oportunidade para a vivência de experiências democráticas, de desenvolvimento da consciência crítica e de intervenção em realidades de forma dialogada com temas/objetos em estudo", também a partir de uma perspectiva freireana.

O desenvolvimento de vínculos entre os seres, a comunhão entre os homens e o diálogo na sua relação com o mundo tornam-se condições para a construção de uma cidadania de caráter planetário. Vínculos amorosos e comprometidos, não apenas entre os sujeitos, mas destes com os seres da Terra - uma oprimida, segundo Gadotti (2008), que lembra o amor de Freire por ela e sua luta por princípios éticos fundamentais.

[...] urge que assumamos o dever de lutar pelos princípios éticos fundamentais como o respeito à vida dos seres humanos, à vida dos outros animais, à vida dos pássaros, à vida dos rios e das florestas. Não creio na amorosidade entre mulheres e homens, entre os seres humanos, se não nos tornamos capazes de amar o mundo. A ecologia ganha uma importância fundamental neste fim de século. Ela tem que estar presente em qualquer prática educativa de caráter radical, crítico ou libertador [...]. Neste sentido me parece uma contradição lamentável fazer um discurso progressista, revolucionário, e ter uma prática negadora da vida. Prática poluidora do mar, das águas, dos campos, devastadora das matas, destruidora das árvores, ameaçadora dos animais e das aves (FREIRE apud GADOTTI, 2008, p. 66).

Apesar de se considerar um cidadão do mundo e de sua obra ser conhecida em diversos países, não nos deparamos em seus livros estudados com adjetivos à palavra cidadania, tais como global e planetária, expressões semelhantes na escala, mas distintas quanto aos aspectos ideológicos. Nita Freire (2009), em reflexão sobre a "cidadania global" a partir da obra de seu marido, alerta para o fato de que a expressão pode gerar ambiguidade de interpretação e remeter à defesa de uma sociedade aos moldes neoliberais em nível mundial. O cuidado com as palavras já era uma ênfase de Freire, que via a palavra como práxis.

\section{CONSIDERAÇÕES FINAIS}

A participação ativa em torno de interesses coletivos é uma das expressões fortes de cidadania. A palavra é camaleônica, pode se adequar a diferentes visões de mundo e dos seres, a interesses distintos. Seria necessário conceber criticamente essa expressão para situá-la em uma perspectiva emancipatória de educação.

Este trabalho admite que a cidadania não seria uma condição a priori dos sujeitos nas sociedades democráticas, mas uma qualidade que deriva do 
permanente processo de conscientização que, na acepção de Freire (1979), exige compromisso histórico/engajamento, para a transformação da realidade que destrói e oprime. A cidadania também não poderia estar restrita aos Estados-nação, porque o processo de globalização escancarou a interligação das ações humanas sobre os povos, os outros seres e a natureza.

Tendo em vista o estudo desenvolvido - ainda que em caráter introdutório -, compreendemos cidadania como uma condição permanentemente conquistada por meio do desenvolvimento da consciência crítica, que implica práticas baseadas em referenciais éticos e sociais que promovam mais vida a todos os seres e a Terra, rumo à construção de uma sociedade de caráter planetário.

Esta ideia seria adequada às discussões e práticas de educação cidadã, que consideram que a formação para a cidadania só é possível "pela cidadania" (AZEVEDO, 2007; GADOTTI, 2010).Também atenderia, nessa visão emancipatória, a esta que seria uma das finalidades da educação nacional (BRASIL, 1988, 1996). Por fim, tal compreensão estaria condizente com a obra e o legado freireanos. O mundo carece de novas realidades, respeitosas da diversidade, comprometidas com a equidade, a sustentabilidade e a amorosidade com os seres. Uma cidadania de caráter planetário.

Artigo recebido em: 08/12/2016 Aprovado para publicação em: 25/01/2017

\section{A CONCEPTION OF (PLANETARY) CITIZENSHIP FOR CITIZEN TRAINING}

ABSTRACT:This work presents an understanding of citizenship from the study of the work of Paulo Freire $(1979,2001,2009 \mathrm{~b})$ due to his contributions to citizen education. It is argued that citizenship can be understood as a permanent condition achieved through the development of critical consciousness. The investigation started from a content analysis, considering methodological subsidiaries of Bardin (1988). But, above all, it is based on the concept of "consciousness" in Freire (1979), whose process could promote the active participation of the subjects to construct new realities, in agreement with contemporary visions that associate citizenship with active participation in all world. In the end, a citizenship of a planetary character is appropriately identified in the discussions and practices of citizen education.

KEYWORDS: Paulo Freire. Planetary citizenship. Education. Consciousness. 


\section{UNA CONCEPCIÓN DE CIUDADANÍA (PLANETARIA) PARA LA FORMACIÓN CIUDADANA}

RESUMEN: Este artículo presenta una comprensión de ciudadanía basada en el estudio de la obra de Paulo Freire $(1979,2001,2009 b)$ debido a sus contribuciones para la educación ciudadana. Se defiende que la ciudadanía puede ser comprendida como una condición permanente conquistada a través del desarrollo de la conciencia crítica. La investigación se inició a partir de un análisis de contenido, fundamentado en las bases metodológicas de Bardin (1988) y, esencialmente, en el concepto de "concientización" de Freire (1979), cuyo proceso podría promover la participación activa de los sujetos en la construcción de otras realidades más armónicas con las ideas contemporáneas que vinculan la ciudadanía a la participación activa en todo el planeta. Al final, una ciudadanía de carácter planetario es identificada más adecuada para la práctica y discusión de la educación ciudadana.

Palabras clave: Paulo Freire. Ciudadanía planetaria. Educación. Concientización .

\section{NOTAS}

1 Parte deste artigo deriva da tese Educação cidadã a distância: uma perspectiva emancipatória a partir de Paulo Freire (CARVALHO, 2015).

2 Grosso modo, a expressão "educação cidadã" pode ser referir à formação pela cidadania, contrária a valores e práticas impostas pela ideologia de mercado. Na tese de Carvalho (2015), que deu origem a este artigo, há um capítulo dedicado à "educação cidadã".

3 "Conferência pronunciada por Paulo Freire no Centro Intercultural de Documentação (CIDOC) em Cuernavaca, Morelos (México)" "e publicada, sob este título, em Contacto. Secretariado Social Mexicano, México, n. 1, ano 8, 1971, p. 42-51" foi reproduzida em Torres $(2014$, p. 73 - 82). Essas informações entre aspas constam em nota de rodapé, na p. 73.

4 Neste trabalho, compreendemos globalização pelo olhar de Boaventura de Souza Santos (1997, p. 14), que trabalha com uma definição "mais sensível às dimensões sociais, políticas e culturais", não restrita à economia mundial. Para Santos, "aquilo que habitualmente designamos por globalização são, de facto, conjuntos diferenciados de relações sociais" que, portanto, "dão origem a diferentes fenômenos de globalização. Nestes termos, não existe estritamente uma entidade única chamada globalização; existem, em vez disso, globalizações". De modo geral, no entanto, ele propõe a seguinte definição: "a globalização é o processo pelo qual determinada condição ou entidade local estende sua influência a todo o globo e, ao fazê-lo, desenvolve a capacidade de designar como local outra condição social ou entidade rival" (SANTOS, 1997, p. 14). 
5 Segundo Cortina (2002, s. p.), desde o último terço do século XX, "a racionalidade mesológica, a que entende de meios mais do que de fins".

6 A cidadania cosmopolita é aquela em que todos os seres humanos se reconheçam e se sintam cidadãos do mundo (CORTINA, 2002).

7 "Por isso que se pergunta: os direitos dos cidadãos se especificam e se definem apenas em relação à entidade política do Estado-nação? [...] no contexto contemporâneo, já não é possível", acredita Lozano (1996, s. p).

8 "seres humanos e cidadãos do planeta; cidadãos do planeta Terra que vivem e compartilham uma comunidade de destino", afirma Morin (2010, p. 437, grifo do autor).

9 Segundo Lozano (1996, s. p.), a "ecologia” tem contribuído com a ideia, nesse contexto, de cidadão global com raízes socioculturais, vinculado a um lugar, "e com uma solidariedade, com a liberdade e os direitos de todos os seres que habitam a terra".

10“na existência de vínculos entre os seres humanos ou com a natureza, ou na capacidade de criá-los, mas sabendo que é de lei cumprir os pactos [...]"(CORTINA, 2002, s. p.).

\section{REFERÊNCIAS}

AGÊNCIA DA ONU PARA REFUGIADOS. Tendências globais sobre refugiados e outras populações de interesse do ACNUR. Jun. 2016. Disponível em: < http://www.acnur. org/portugues/recursos/estatisticas/>. Acesso em: 11 fev. 2017.

ALMEIDA, F. J. de. Escola, currículo, tecnologias e desenvolvimento sustentável. Revista Científica e-curriculum, v. 7, n. 1, 2011. Disponível em: <http://revistas.pucsp.br/index. php/curriculum/article/view/5633>. Acesso em: 27 jan. 2015.

AZEVEDO, J. C. de. Reconversão cultural da escola: mercoescola e escola cidadã. Porto Alegre: Sulina: Universitária Metodista, 2007.

BARDIN, L. Análise de conteúdo. Lisboa: Edições 70, 1988.

BIESTA, G. Para além da aprendizagem: educação democrática para um futuro humano. Belo Horizonte: Autêntica Editora, 2013. (Coleção Educação: experiência e sentido).

BRASIL. Constituição da República Federativa do Brasil. Brasília: Senado Federal: Centro Gráfico, 1988.

Lei n० 9.394, de 20 de dezembro de 1996. Estabelece as diretrizes e bases da educação nacional. Brasília: MEC/Inep/Gráfica do Senado, 1996.

CARVALHO, J. de S. Educação cidadã a distância: uma perspectiva emancipatória a partir de Paulo Freire. 2015. 211 f. Tese (Doutorado) - Faculdade de Educação da Universidade de São Paulo, São Paulo, 2015.

. Educação a distância e movimentos sociais em rede: articulação para formação cidadã. In: PEDRO, Neusa et al. (Org.). Digital technologies \& future School. Lisboa: Instituto de Educação da Universidade de Lisboa, 2016, v. 1, p. 1148-1159 
CORTINA, A. Ciudadanía cosmopolita: de los derechos a las responsabilidades. Debats, n. 77, 2002. Disponível em: <http://www.alfonselmagnanim.com/debats/77/ quadern02.htm>. Acesso em: 30 out. 2012.

. Ciudadanos del mundo: hacia una teoría de la ciudadania. Madrid: Alianza Editorial, 2009.

CASTELLS, M. Redes de indignação e esperança: movimentos sociais na era da internet. Versão eletrônica. Rio de Janeiro: Zahar, 2013.

EQUIPE FORNTEIRAS. Manuel Castells analisa as manifestações brasileiras. Fronteiras do Pensamento, 15 jun. 2013. Disponível em: <http://www.fronteiras.com/artigos/ manuel-castells-analisa-as-manifestacoes-civis-brasileiras>. Acesso em: 18 jun. 2013.

FREIRE, N. Contribuições de Paulo Freire para a pedagogia critica: Educação emancipatória: a influência de Paulo Freire na cidadania global ou A influência de Paulo Freire na educação para a autonomia e a libertação. Teoría de la Educación. Educación y Cultura en la Sociedad de la Información, v. 10, n. 3, p. 141-158, 2009.

FREIRE, P. Conscientização: teoria e prática da libertação. São Paulo: Cortez, 1979. . À sombra desta mangueira. São Carlos: Olho D'Água, 1995.

. Pedagogia da autonomia: saberes necessários à prática educativa. 25. ed. Rio de Janeiro: Paz e Terra, 1996. . Política e educação: ensaios. 5. ed. São Paulo: Cortez, 2001. .Educação como prática da liberdade. 32. ed. Rio de Janeiro: Paz e Terra, 2009a. . Pedagogia da esperança: um reencontro com a pedagogia do oprimido. 16. ed. São Paulo: Paz e Terra, 2009b.

GADOTTI, M. Educar para a sustentabilidade: uma contribuição à década da educação para o desenvolvimento sustentável. São Paulo: Editora e Livraria Instituto Paulo Freire, 2008. (Unifreire, 2).

. Escola cidadã. 13. ed. São Paulo: Cortez, 2010.

GIDDENS, A.; SUTTON, P. W. Conceitos essenciais da sociologia. São Paulo: Unesp, 2016.

GIL-JAURENA, I. et al. Investigación sobre aprendizaje de la ciudadanía activa. In: $5^{\circ}$ COLOQUIO INTERNACIONAL DE ANIMACIÓN SOCIOCULTURAL, 26 out. 2011, Zaragoza. Anais... Zaragoza: [s.n.], 26 out. 2011.

HERBERT, S. P. Cidadania. In: STRECK, D. R.; REDIN, E. ZITKOSKI, J. J. (Org.). Dicionário Paulo Freire. 2. ed. Belo Horizonte: Autêntica, 2010. p. 67-68.

IANNI, O. A sociedade global. Rio de Janeiro: Paz e Terra, 1996.

LLORENTE CORTÉS, M. A.. Ciudadanía y participación: documento de debate. In: III CONGRESO DE EDUCACIÓN PARA EL DESARROLLO, diciembre 2006, Vitoria-Gasteiz. 
Anais... Vitoria-Gasteiz: [s.n.], diciembre 2006. Disponível em: <http://www.hegoa.ehu. es/congreso/gasteiz/doku/CiuParDeb.pdf>. Acesso em: 15 out. 2012.

LOZANO, J. Ciudadania ampliada. La emergencia de la ciudadania cultural e ecologica. Razón y Palabra, n. 5, dez.1996. Disponível em: <http://www.razonypalabra.org.mx/ anteriores/n5/ciudad.htm>. Acesso em: 29 out. 2012.

MORIN, Edgar. Los principios fundamentales de la educación del siglo XXI (entrevista concedida a Antonio Roveda H). Signo y Pensamiento, Bogotá, v. 29, n. 56, p. 42-49, jan./jun. 2010.

PARO, V. H. Educação para a democracia: o elemento que falta na discussão da qualidade do ensino. Revista portuguesa de educação, Minho, v. 13, n. 1, p. 23-38, 2000.

ROLNIK, R. Em torno do direito de ir e vir: existe diálogo em SP? Blog da Raquel Rolnik, 14 jun 2013. Disponível em: <http://raquelrolnik.wordpress.com/2013/06/14/em-torno-do-direito-de-ir-e-vir-existe-dialogo-em-sp/>. Acesso em: 17 jun. 2013.

SANTOS, B. de S. Por uma concepção multicultural de direitos. Revista Crítica de Ciências Sociais, Coimbra, n. 48, p. 11-32, jun. 1997.

.Vamos falar da sociedade civil planetária. In: FÓRUM SOCIAL MUNDIAL, 2002, Porto Alegre. Anais... Porto Alegre: [s.n.], 2002. Disponível em: <http://www.ciranda. net/ciranda-mundi/article/vamos-falar-da-sociedade-civil>. Acesso em: 30 out. 2012. TORRES, C. A. A pedagogia política de Paulo Freire. In: APPLE, M. W.; NÓVOA, A. Paulo Freire: política e pedagogia. Porto: Porto Editora, 1998. p. 47-67.

. Diálogo e práxis educativa: uma leitura crítica de Paulo Freire. São Paulo: Edições Loyola, 2014.

ZITKOSKI, J. J. Ser mais. In: STRECK, D. R.; REDIN, E. ZITKOSKI, J. J. (Org.). Dicionário Paulo Freire. 2. ed. Belo Horizonte: Autêntica, 2010. p. 369-370.

Jaciara de SÁ Carvalho é doutora e mestre em Educação pela Unversidade de São Paulo (USP). Professora adjunta no Programa de Pós- Graduação em Educação da Universidade Estácio de Sá (UNESA), vinculada à linha Tecnologias da Informação e da Comunicação nos Processos Educacionais (TICPE). Suas pesquisas abordam as seguintes temáticas: educação, tecnologia, Paulo Freire, comunicação e cidadania. E-mail: jsacarvalho@smail.com 